\title{
TAREFAS MATEMÁTICAS DESENCADEADORAS DE OBJETIVOS E COMPETÊNCIAS DA EDUCAÇÃO FINANCEIRA
}

\author{
Daniela Harmuch* \\ Marcele Tavares Mendes**
}

RESUMO: O presente trabalho apresenta uma discussão de tarefas matemáticas que abordam objetivos e competências da Educação Financeira, tarefas elaboradas com base nos pressupostos da Educação Matemática Realística. Como atividades econômicas são uma das mais recorrentes formas de manifestação da matemática no cotidiano, ideias e conceitos matemáticos podem ser reconhecidos como ferramentas que servem aos contextos financeiros. As tarefas foram aplicadas a estudantes do $8^{\circ}$ ano do Ensino Fundamental de uma escola pública estadual em Londrina-PR, no segundo semestre de 2015. Por meio dessa experiência, buscou-se evidenciar possibilidades para o desenvolvimento de competências matemáticas, relacionando-as a aspectos da Educação Financeira, assim como o desenvolvimento de competências de um sujeito matematicamente letrado a partir do lidar com tarefas autênticas aquelas com contexto de relevância prática e que favorecem ao aluno abordar e mostrar suas competências.

PALAVRAS-CHAVE: Educação Matemática; Educação Financeira; Tarefas; Letramento Matemático.

\section{MATHEMATICAL TASKS TRIGGERING AIMS AND COMPETENCES OF FINANCIAL EDUCATION}

\begin{abstract}
Mathematical tasks that deal with objectives and competences of financial education and tasks based on the presuppositions of realistic mathematic education are discussed. Since economic performance is one of the most current forms of mathematics in day-to-day activities, mathematical ideas and concepts may be acknowledged as tools within financial contexts. Several tasks were given to Year 8 students of a government-run school in Londrina, Brazil, late in 2015. The experience brought forth possibilities for the development of mathematical competences and

Mestre em Ensino de Matemática pela Universidade Tecnológica Federal do Paraná (UTFPR) campus de Londrina, PR, Brasil. E-mail: dharmuch@yahoo.com.br

** Doutora em Ensino de Ciências e Educação Matemática pela Universidade Estadual de Londrina (UEL). Docente do Depto. de Matemática da Universidade Tecnológica Federal do Paraná (UTFPR) campus Londrina, Londrina-PR e, Docente Programa de Mestrado Profissional em Ensino de Matemática pela Universidade Tecnológica Federal do Paraná (UTFPR) campus de Londrina/Cornélio Procópio, Paraná, Brasil
\end{abstract}


their relation to aspects of financial education. The development of competences of a mathematically literate person dealing with authentic tasks is thus analyzed. The latter are characterized by practical relevance since they require that students reveal their competences.

KEY WORDS: Mathematical education; Financial education; Tasks; Mathematical literacy.

\section{INTRODUÇÃO}

Este artigo apresenta uma discussão de tarefas matemáticas que fazem parte de uma sequência de tarefas elaborada ao longo da pesquisa de mestrado da primeira autora sob orientação da segunda autora, no Programa de Pós-Graduação em Ensino de Matemática, da Universidade Tecnológica Federal do Paraná, Londrina/ Cornélio Procópio.

O objetivo geral da pesquisa de mestrado foi elaborar, aplicar e discutir tarefas matemáticas que provocam reflexões a respeito de temas da Educação Financeira à luz da abordagem de ensino da Educação Matemática Realística. Nossas reflexões aqui promulgadas são subsidiadas pela análise da produção escrita e de áudios de alunos do $8^{\circ}$ ano do Ensino Fundamental de uma escola pública estadual em Londrina-PR, no segundo semestre de 2015 , em que a primeira autora era a regente da turma.

A dinâmica da sala de aula, assim como a discussão teórica, fundamenta-se nos pressupostos de ensino e de aprendizagem da Educação Matemática Realística RME, abordagem de ensino cujo desenvolvimento foi inspirado, principalmente, nas ideias e contribuições de Hans Freudenthal (1905-1990). De modo particular, esses pressupostos estão intimamente ligados às atitudes da professora/pesquisadora ${ }^{3}$.

A Sequências de Tarefas, em particular a tarefa discutida, tem por objetivo fomentar um ambiente de sala de aula à luz da RME e favorecer que os alunos desenvolvam comportamentos financeiros autônomos e saudáveis. Esse comportamento está associado aos princípios apresentados para um modelo pedagógico elaborado pela $\mathrm{OCDE}^{4}$, o qual:

\footnotetext{
A professora/pesquisadora é, neste trabalho, compreendida como a responsável pela docência e aplicação da atividade investigada e, ao mesmo tempo, pesquisadora de sua própria prática.

4 Organização para Cooperação e Desenvolvimento Econômico (OCDE).
} 
foi concebido para oferecer ao aluno informações e orientações que favoreçam a construção de um pensamento financeiro consistente e o desenvolvimento de comportamentos autônomos e saudáveis, para que ele possa, como protagonista de sua história, planejar e fazer acontecer a vida que deseja para si próprio, em conexão com o grupo familiar e social a que pertence. Nesse sentido, o foco do trabalho recai sobre as situações cotidianas da vida do aluno, porque é nelas que se encontram os dilemas financeiros que ele precisará para resolver (BRASIL/COREMEC, 2010, p. 7).

Conforme Mendes e Harmuch (2016, p. 11), "assuntos da Educação Financeira são fenômenos ricos a serem matematizados por jovens, permitindo à matemática ser reconhecida como um meio de organizar situações e não um fim”. Essas tarefas oferecem aos alunos a oportunidade de refletir e desenvolver bons hábitos econômicos para as suas necessidades reais, como saber lidar com cálculos em situações de compras no mercado, determinação do valor real do produto.

De modo restrito, evidenciamos que os contextos envolvidos, como os princípios da RME favorecem que os alunos desenvolvam objetivos da Educação Financeira, assim como competências de um sujeito matematicamente letrado. Subjacente a essa discussão, realçamos aspectos da reinvenção guiada (estratégia de ensino da RME), evidenciando que o papel do professor em uma aula à luz da RME é o de intervir e orientar o processo de construção do conhecimento de seus alunos.

Para tanto, como ponto de partida, apresentamos uma seção a respeito do letramento matemático e dos pressupostos da RME e, em seguida uma acerca da Educação Financeira. Destacamos também os aspectos dos procedimentos metodológicos considerados no desenvolvimento da pesquisa, em particular os da tarefa discutida. Com base na construção teórica, apresentamos uma discussão particular a partir de produções dos alunos ao lidar com a tarefa selecionada. Na sequência com nossas considerações finais, seguidas das referências bibliográficas.

\section{LETRAMENTO MATEMÁTICO E RME}

Se o objetivo maior da educação é promover mudanças na maneira como o estudante vê e participa do mundo em que vive, então na escola é preciso desenvolver a capacidade de "solucionar problemas em contextos apropriados, de maneira a ser capaz de transferir essa capacidade de resolução de problemas para os contextos 
do mundo social e, especialmente, do mundo produtivo" (LOPES, 2002, p. 396). Desenvolver essa capacidade equivale a desenvolver o letramento matemático, que corresponde à:

capacidade que o indivíduo tem em identificar e compreender o papel que a matemática desempenha no mundo, de fazer julgamentos bem fundamentados, e de usar a Matemática de modo a atender as suas necessidades presentes e futuras como cidadão construtivo, interessado e reflexivo (OECD, 1999 apud De LANGE, 2003).

Desenvolver essas capacidades requer que a matemática em contexto de sala de aula reforce seu papel social, promova o acesso e o desenvolvimento de estratégias e possibilidades de leitura do mundo, para os quais conceitos e relações, critérios e procedimentos, resultados e culturas matemáticos possam contribuir (FONSECA, 2004).

O letramento matemático não se limita ao conhecimento da terminologia, dos dados e dos procedimentos matemáticos, ainda que os inclua, tampouco se limita às destrezas para realizar certas operações e cumprir com certos métodos. Desenvolver competências matemáticas implica em desenvolver a capacidade de combinar esses elementos para satisfazer as necessidades da vida real dos indivíduos na sociedade.

Para tanto, é desejável uma sala de aula na qual as tarefas requeiram, para além de competências de reprodução, competências que demandem tomadas de decisão e que reflitam contextos do mundo social. Uma aula à luz da RME valoriza a utilização de tarefas realísticas ${ }^{5}$ e significativas em sala de aula.

A Educação Matemática Realística contrapõe os pressupostos de uma matemática como ciência acabada, a-histórica e organizada logicamente, considera a matemática como uma atividade humana, como outras atividades tais como a palavra, a escrita e o desenho, e a situa "entre as primeiras atividades cognitivas conhecidas e a primeira disciplina a ser ensinada, mas que evoluiu e transformou-se sob a influência das modificações sociais, bem como a sua filosofia e a maneira de ser ensinada" (FREUDENTHAL, 1979, p. 321).

\footnotetext{
Realístico é tradução do termo 'realistic', que tem origem no verbo neerlandês "zich realiseren" e pode assumir o mesmo significado de "imaginar", que, segundo Van Den Heuvel-Panhuizen, sugere que os contextos ou situações nos quais os estudantes se envolvem não precisam ser "reais", mas precisam ser imagináveis, realizáveis, concebíveis na mente dos estudantes (VAN DEN HEUVEL-PANHUIZEN, 2005 apud BURIASCO; FERREIRA; CIANI, 2009)
} 
Para Freudenthal (1971), a matemática como atividade humana é

uma atividade de resolver problemas, de procurar problemas, e também uma atividade de organização de um assunto. Esta pode ser uma questão da realidade, a qual tem de ser organizada de acordo com padrões matemáticos se tiver de ser resolvida. Também pode ser uma questão matemática, resultados novos ou velhos de produção própria ou de outros, que têm de ser organizados de acordo com novas ideias, para ser melhor entendida, em um contexto mais amplo ou por uma abordagem axiomática (FREUDENTHAL, 1971, p. 414)

Na perspectiva da RME, a matemática torna-se um meio de organizar uma situação e deve ser conectada à realidade para que possa ser de valor humano (VAN DEN HEUVEL-PANHUIZEN, 2001), e aos estudantes deve ser dada a oportunidade "guiada" para "reinventá-la", (FREUDENTHAL, 1979, 1991; GRAVEMEIJER, 2005). O professor é aquele que guia e acompanha a produção do aluno, tendo a responsabilidade de criar oportunidades de aprendizagem por meio de tarefas. Ao aluno é dada a oportunidade de "inventar" algo que é novo para ele, mas bem conhecido para o professor.

À luz desses pressupostos de matemática, de ensino e de aprendizagem, nos debruçamos em organizar tarefas matemáticas para que, guiados pelo professor, os alunos possam construir conceitos formalizados referentes à Educação Financeira, uma vez que a atividade econômica tem destaque entre os diversos fenômenos que necessitam de ideias e de conceitos matemáticos enquanto recursos para seu entendimento e desenvolvimento. Essas tarefas podem ser encontradas em Harmuch (2017).

\section{EDUCAÇÃO MATEMÁTICA FINANCEIRA}

Entre as múltiplas formas de manifestação da matemática no cotidiano, talvez a mais recorrente seja a atividade econômica. Dessa forma, avaliar as estratégias matemáticas em contextos financeiros interessa à Educação Matemática.

O lidar com assuntos da Educação Financeira em aulas de matemática faz-se pertinente e necessário, sobretudo no esforço de promover o conhecimento mate- 
mático escolar, conferir significados econômicos aos problemas matemáticos e viceversa, explorando-se bidirecionalmente a importância do contexto, na construção de sentido e na solução de problemas (HOFMANN, MORO, 2011).

Aspectos da Educação Financeira são tratados como tema transversal - "trabalho e consumo" - nos Parâmetros Curriculares Nacionais de Matemática (BRASIL, 1998). Nesses documentos, conforme Mendes e Harmuch (2016), apresenta-se

a necessidade dos alunos se posicionarem criticamente diante do consumismo de bens supérfluos e vitais e compreenderem que grande parte do que se consome é produto do trabalho, embora nem sempre se pense nessa relação no momento em que se adquire uma mercadoria; a necessidade de discutir o custo da produção com o preço de mercado, favorecendo para compreensão da política de maximização do lucro e precarização do valor do trabalho; a necessidade de analisar a composição e a qualidade dos produtos e avaliar seu impacto sobre a saúde e o meio ambiente (MENDES; HARMUCH, 2016, p. 3).

A Organização para Cooperação e Desenvolvimento Econômico (OCDE) redigiu um documento que apresenta a Estratégia Nacional de Educação Financeira (ENEF). Nesse documento define Educação Financeira como

o processo mediante o qual os indivíduos e as sociedades melhoram sua compreensão em relação aos conceitos e produtos financeiros, de maneira que, com informação, formação e orientação, possam desenvolver os valores e as competências necessários para se tornarem mais conscientes das oportunidades e dos riscos nele envolvidos e, então, poderem fazer escolhas bem informadas, saber onde procurar ajuda, adotar outras ações que melhorem o seu bem-estar. Assim, podem contribuir de modo mais consciente para a formação de indivíduos e sociedades responsáveis, comprometidos com o futuro (BRASIL, 2011, p. 57-58).

Esse documento, ENEF (2011) sugere um modelo pedagógico com objetivos que envolvem duas dimensões, espacial e temporal, uma vez que o cotidiano acontece sempre em um espaço e um tempo determinado. O Quadro 1 apresenta seus sete objetivos, separados nas duas dimensões mencionadas e ramificados em dez competências. 
Quadro 1. Objetivos e competências da Educação Financeira

\begin{tabular}{|c|c|c|c|c|}
\hline \multicolumn{3}{|r|}{ OBJETIVOS } & \multicolumn{2}{|r|}{ COMPETÊNCIAS } \\
\hline \multirow{4}{*}{ 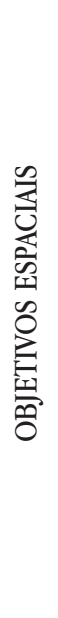 } & OB1 & Formar para a cidadania. & $\mathrm{C} 01$ & Debater direitos e deveres. \\
\hline & OB2 & $\begin{array}{l}\text { Ensinar a consumir e a poupar } \\
\text { de modo ético, consciente e re- } \\
\text { sponsável. }\end{array}$ & $\begin{array}{l}\mathrm{C} 02 \\
\mathrm{C} 03\end{array}$ & $\begin{array}{l}\text { Tomar decisões financeiras social e ambien- } \\
\text { talmente responsáveis. } \\
\text { Harmonizar desejos e necessidades no } \\
\text { planejamento financeiro do projeto de vida. }\end{array}$ \\
\hline & OB3 & $\begin{array}{l}\text { Oferecer conceitos e ferramen- } \\
\text { tas para tomada de decisão } \\
\text { autônoma baseada em mu- } \\
\text { dança de atitude. }\end{array}$ & $\begin{array}{l}\mathrm{C} 04 \\
\mathrm{C} 05 \\
\mathrm{C} 06\end{array}$ & $\begin{array}{l}\text { Ler e interpretar textos específicos de Edu- } \\
\text { cação Financeira. } \\
\text { Ler criticamente textos publicitários. } \\
\text { Tomar decisões financeiras autônomas de } \\
\text { acordo com suas reais necessidades. }\end{array}$ \\
\hline & OB4 & Formar multiplicadores. & $\mathrm{C} 07$ & Atuar como multiplicador. \\
\hline \multirow{3}{*}{ 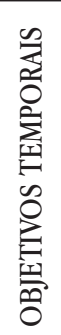 } & OB5 & $\begin{array}{l}\text { Ensinar a planejar em curto, } \\
\text { médio e longo prazos. }\end{array}$ & C08 & Elaborar planejamento financeiro. \\
\hline & OB6 & $\begin{array}{l}\text { Desenvolver a cultura da pre- } \\
\text { venção. }\end{array}$ & C09 & $\begin{array}{l}\text { Analisar alternativas de prevenção em longo } \\
\text { prazo. }\end{array}$ \\
\hline & OB7 & $\begin{array}{l}\text { Proporcionar a possibilidade } \\
\text { de mudança da condição atual. }\end{array}$ & C10 & $\begin{array}{l}\text { Analisar alternativas para superar dificul- } \\
\text { dades econômicas. }\end{array}$ \\
\hline
\end{tabular}

Fonte: (BRASIL/COREMEC, 2010, p. 6)

Oportunizar aos estudantes lidar com tarefas que envolvam aspectos da Educação Financeira em aulas de matemática - aulas à luz da RME é um caminho defendido neste trabalho na direção de favorecer uma educação que alcance o que é proposto nas Diretrizes educacionais e pela ENEF. Conforme Mendes e Harmuch (2016), transparece o desafio de organizar tarefas de matemática, em ambientes que ofereçam aos estudantes oportunidades para matematizar, para "reinventar" matemática, que possibilitam explorar a intuição e a capacidade de organizar matematicamente, situações que sejam "realizáveis" para que, guiados pelo professor, os estudantes possam desenvolver competências e construir conceitos formalizados referentes à Educação Financeira. 


\section{ASPECTOS METODOLÓGICOS DA EXPERIÊNCIA RELATADA}

Os aspectos metodológicos aqui apresentados serviram a uma pesquisa qualitativa de cunho interpretativo, cujo objetivo foi elaborar, aplicar e discutir tarefas matemáticas que provocam reflexões a respeito de temas da Educação Financeira à luz da abordagem de ensino da Educação Matemática Realística. Ao final da pesquisa, formou-se um conjunto de 12 tarefas, que foram organizadas como uma Sequência de Tarefas, que pode ser consultada em Harmuch (2017). É apresentada também uma possível dinâmica de organização pedagógica à luz dos pressupostos da RME, assim como objetivos e competências (Quadro 1), que poderão ser trabalhados, e uma previsão de possíveis produções de alunos.

A Sequência de Tarefas foi organizada para ser desenvolvida em 3 oficinas de 4 horas. O Quadro 2 apresenta o tema de cada uma das oficinas, com o respectivo número das tarefas trabalhadas em cada encontro. Neste trabalho apresentamos uma discussão da Tarefa 8.

Quadro 2. Temas e Organização das Tarefas

\begin{tabular}{|c|c|c|}
\hline Organização & \multicolumn{1}{|c|}{ Tema } & Tarefas \\
\hline Oficina 1 & $\begin{array}{l}\text { A busca do conceito de felicidade - uma reflexão do } \\
\text { custo de vida e estratégias de economia doméstica. }\end{array}$ & Tarefas 1, 2, 3, 4 e 5 \\
\hline Oficina 2 & $\begin{array}{l}\text { Gastos pequenos precisam ser controlados, pois } \\
\text { eles se acumulam e podem se tornar gastos grandes. }\end{array}$ & Tarefas 6, 7, 8, 9 \\
\hline Oficina 3 & $\begin{array}{l}\text { Como devo agir em situações reais diversas relacio- } \\
\text { nadas ao quesito financeiro? }\end{array}$ & Tarefas 10, 11 e 12 \\
\hline
\end{tabular}

Fonte: (HARMUCH, 2017)

A Figura 1 apresenta as situações que compõem a tarefa discutida. 


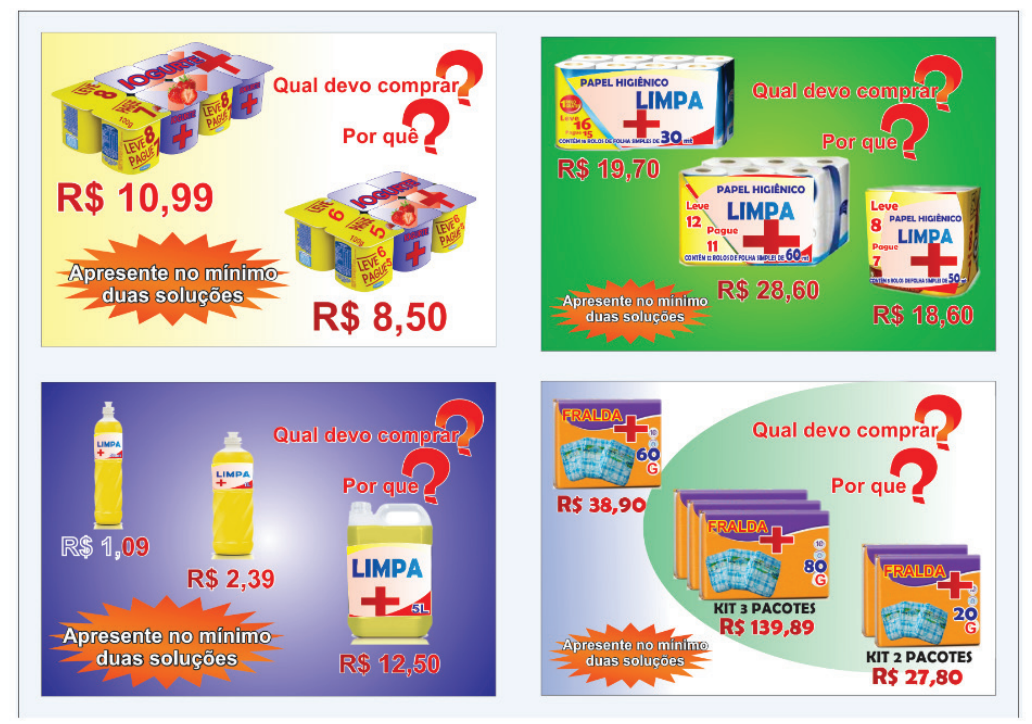

Figura 1. Situações apresentadas aos alunos.

Fonte: autoras.

A discussão aqui apresentada parte de uma primeira aplicação de tarefas da Sequência de Tarefas elaborada por Harmuch (2017). Especificamente nessa tarefa, espera-se que as situações trabalhadas à luz da RME favoreçam discussões para tentar alcançar os objetivos e desenvolver as competências apresentadas no Quadro 3.

Quadro 3. Objetivos e Competências da Tarefa 8

\begin{tabular}{|c|c|c|c|c|c|c|c|c|c|c|}
\hline \multirow{2}{*}{$\begin{array}{l}\text { Objetivos Específicos da } \\
\text { Educação Financeira }\end{array}$} & \multicolumn{10}{|c|}{ COMPETÊNCIAS } \\
\hline & C1 & $\mathrm{C} 2$ & C3 & C4 & C5 & C6 & C7 & C8 & C9 & C10 \\
\hline $\begin{array}{l}\text { Compreender que há comportamentos que } \\
\text { nos levam a gastar mais dinheiro do que o } \\
\text { previsto em determinadas situações; } \\
\text { Distinguir os comportamentos positivos } \\
\text { dos negativos na hora de tomar algumas de- } \\
\text { cisões envolvendo o financeiro; } \\
\text { Saber e aplicar a matemática para resoluções } \\
\text { nas escolhas de produtos; } \\
\text { Saber identificar qual o real custo de deter- } \\
\text { minados produtos. }\end{array}$ & & $\mathbf{X}$ & $\mathbf{X}$ & & $\mathbf{X}$ & $\mathbf{X}$ & $\mathbf{X}$ & $\mathbf{X}$ & $\mathbf{X}$ & $\mathbf{X}$ \\
\hline
\end{tabular}

Fonte: autoras. 
A tarefa foi aplicada em uma turma de $8^{\circ}$ ano do Ensino Fundamental, do período vespertino, em uma escola pública estadual em Londrina-PR, durante o segundo semestre do ano de 2015, com o tempo de 100 minutos e com a presença de 24 alunos. É preciso destacar que a professora-pesquisadora era regente dessa turma.

Os dados são frutos das gravações de áudio transcritas, das fotos e do diário de campo, com o consentimento legal dos alunos, de seus responsáveis e da Instituição. Nesse texto, cada aluno foi designado pela letra $\mathrm{A}$, seguida de um número de 1 a 24 e a professora designada por $\mathrm{P}$. O recorte aqui apresentado refere-se a algumas falas dos estudantes nas discussões das tarefas, com a intenção de evidenciar aspectos de uma Educação Financeira, em tarefas de matemática em aulas à luz da RME.

\section{UM OLHAR SOBRE O AMBIENTE - ALGUMAS CONSIDERAÇÕES}

Os alunos foram organizados em pequenos grupos. Em uma aula à luz da RME, o desenvolvimento de uma atividade em grupo é tomado como uma oportunidade de aprendizagem, uma vez que a aprendizagem é tomada como um construto das interações com o mundo (VAN DEN HEUVEL-PANHUIZEN, 2010).

Aos alunos foram apresentadas quatro situações distintas para resolverem, que simulavam uma decisão a ser tomada em compras no mercado, conforme apresentado na Figura 1. Em todas elas havia as mesmas perguntas e a solicitação de, no mínimo, duas soluções pertinentes. As situações envolviam contextos que podem ser imaginados pelos alunos, e a matemática torna-se ferramenta para organizá-las. Isso vai ao encontro do princípio da realidade da RME, a qual sugere que aos alunos seja dada oportunidade de organizar a realidade por meio de ideias e conceitos matemáticos (VAN DEN HEUVEL-PANHUIZEN, 2000).

Ao solicitar que os alunos apresentem mais de um modo de lidar com a situação, sugere-se que, apesar de a situação ser "resolvida" por ideias e conceitos matemáticos, ela pode ser interpretada para além dos resultados matemáticos e que a matemática não deve ser um fim em si mesma, mas como ser um apoio para tomadas de decisões com os reflexos sociais, econômicos e políticos. 
As tarefas foram dispostas em uma mesa central, um lugar da sala em que todos os grupos as enxergavam. Cada grupo de quatro estudantes escolheu com a qual lidar primeiro, tendo o tempo de 15 minutos para esboçar o pensamento no papel. Assim que o grupo achasse conveniente, ou decorrido o tempo limite, escolhia outra, até que as quatro propostas tivessem sido "resolvidas" por todos. Durante a atividade, a professora pesquisadora passava de grupo em grupo, fazendo intervenções e provocando mais questionamentos. Após um tempo, a turma foi disposta em círculo, para discussão com o grupo todo e para a apresentação das formas distintas de solucionar matematicamente as situações ou, convenientemente, conforme as necessidades pessoais.

Nesse contexto, a professora tornou-se guia, com a responsabilidade de criar oportunidades e não mais de deter o conhecimento e/ou de transmiti-lo. $\mathrm{O}$ foco do ensino passou da matemática (produto de um processo de matematização) para o processo de organizar a realidade usando ideias e conceitos matemáticos. Santos $(2014$, p. 40) apresenta alguns aspectos da dinâmica da aula sob a perspectiva da reinvenção guiada, estratégia de ensino da RME:

o trabalho em sala de aula tem início com a proposição de uma situação realística que possibilita diferentes níveis de matematização. após resolverem a situação, os alunos podem interagir uns com os outros e terem a oportunidade de analisar e discutir estratégias e procedimentos que utilizaram.

durante e após o trabalho dos alunos, o professor pode fazer questionamentos para explorar as resoluções que apresentaram bem como as diferenças existentes entre elas, e discutir aspectos matemáticos subjacentes a essas resoluções encorajando-os a se interessar por esses aspectos (SANTOS, 2014, p. 40).

Escolhemos apresentar alguns trechos das discussões dos alunos que remetem à reflexão gerada a partir de duas situações que poderiam ter ficado apenas no campo das operações matemáticas - a do iogurte e a do papel higiênico, mas que serviram para uma reflexão que vai ao encontro de um sujeito que busca compreender suas necessidades e as consequências de suas ações.

$\mathrm{Na}$ proposta do iogurte, havia dois produtos, um com oito Iogurtes (leve 8 e pague 7), outro com seis iogurtes (leve 6 e pague 5), ambos com preços distintos. Os alunos apresentaram mais de uma forma de solucionar. Um grupo descobriu o preço unitário do produto, outro fez equivalência com o produto maior. 
O Quadro 2 apresenta dizeres dos alunos que são exemplos de como a discussão seguiu para além dos elementos matemáticos.

Quadro 4. Trechos de dizeres dos alunos na situação do iogurte

A5 - A diferença entre os dois é $\mathrm{R} \$ 0,04$, às vezes compensa levar o que vem menos, porque estraga.

A16 - É verdade, pois se parar para pensar se pagar dois a mais e estragar, compensa o que vem menos daí você só perde $\mathrm{R} \$ 0,08$. Não é quase nada.

Fonte: autoras

Dessas afirmações derivam as competências C02, C03, C05, C06, C09 e C10 (Quadro 1), pois representam uma decisão, que vai além do preço determinado, na qual o aluno leva em consideração elementos que não estavam agregados à proposta. Por exemplo, julgar interessante levar em consideração o fato de estragar o produto. É uma decisão financeira ambientalmente responsável, harmoniza desejos e necessidades no planejamento de vida, mesmo que a curto prazo, além de ser uma tomada de decisão autônoma, de acordo com as reais necessidades do adolescente. Observamos que está atrelada uma análise implícita de alternativas de prevenção de custo e superação de dificuldades econômicas.

Outro benefício advindo da Educação Financeira, segundo a ENEF 2016, consiste no julgamento crítico que se pode aprender a fazer em relação à publicidade, isso porque uma sociedade marcada pelo consumo se caracteriza em estimular a depreciação e a desvalorização dos produtos, depois de terem sido adquiridos. Essa é a cultura do excesso e da frustração, que aposta na irracionalidade dos consumidores e não nas suas estimativas sóbrias e bem informadas, ou seja, estimula emoções que levam ao consumo impetuoso, em vez de cultivar o uso da razão. A opinião de outros alunos foi uma oportunidade de aprendizagem dada a esse aluno, o qual pode refletir para além de suas necessidades imediatas, refletindo melhor nas questões relacionadas ao consumo. Essa oportunidade é uma característica de uma aula baseada nos princípios da reinvenção guiada.

Em relação à proposta do papel higiênico, os grupos afirmaram ser a mais difícil, por terem de pensar, agora, além de no preço e na quantidade, também a metragem do papel. Um grupo pensou no preço de um metro, em todos os casos, 
para comparar, usando divisões simples. Outro grupo comparou os preços dos 3 produtos dois a dois.

No Quadro 3, apresentamos um trecho da discussão que revela competências da Educação Financeira no momento de avaliar as possíveis decisões.

Quadro 5. Trechos de dizeres dos alunos na situação do papel higiênico

A2 - Vou levar o menor, por ocupar muito espaço em minha casa. Porém papel higiênico não estraga.

A16 - É melhor comprar de 60m para jogar menos rolinho em casa, aquela "partezinha" de dentro.

Fonte: autoras

A discussão seguiu um curso na qual questões de sustentabilidade foram levantadas, competência C02. É uma decisão de consumo de modo ético, consciente e responsável. Entretanto, também era propósito discutir qual era o preço do metro do papel higiênico em cada embalagem e fazer comparações, para que, junto com questões ambientais e de suas necessidades, tomassem a melhor decisão segundo suas opiniões. O aluno A19 trouxe essa oportunidade.

Quadro 6. Trechos de dizeres de A19 na tarefa do papel higiênico

A19 - É preciso tomar cuidado com as táticas de mercado, geralmente produtos que vêm em maior quantidade são mais baratos, e é preciso analisar, pois às vezes não é, né professora?

Fonte: autoras

A fala de A19 oportuniza, para o grupo, reflexões sobre a competência C05, pois interpretar uma oferta publicitária pode mudar a ação de uma compra, oferecendo conceitos e ferramentas para uma tomada de decisão autônoma.

Após essa discussão, a professora pôde questionar como fazer análises e, por fim, abordar que não há uma melhor resposta, que depende de muitas variáveis e que é preciso relacionar diversos aspectos. Segundo os documentos da ENEF, um consumidor consciente, para cumprir sua parcela de responsabilidade, deve tomar uma decisão de compra informada, e considerar os impactos ambientais que ela pode causar, o que significa observar os já referidos padrões de consumo sustentável. 
Uma outra competência da Educação Financeira que deriva dessa Tarefa, e que não conseguimos dimensionar, é se os alunos se tornaram disseminadores das ideias discutidas (C07).

Os trechos analisados indicam que os estudantes interpretam e resolvem as atividades dos problemas propostos pelo viés dos contextos da vida prática, o que vai ao encontro das ideias de Freudenthal (1991), o qual propõe um ensino em que o professor guia os estudantes a utilizar a matemática como um meio de organizar uma situação. Observamos que os alunos puderam interagir uns com os outros e tiveram a oportunidade de analisar e discutir as estratégias e os procedimentos que utilizaram. A professora pode fazer questionamentos para explorar tanto as soluções matemáticas como incentivar aspectos dos objetivos da Educação Financeira adotadas neste trabalho, aspectos de uma aula sob a reinvenção guiada.

\section{CONSIDERAÇÕES FINAIS}

Dois pontos nessa experiência destacaram-se. Primeiro, o fato de o contexto de sala de aula ter favorecido aos alunos lidar com as tarefas para além de resoluções que fizessem uso de técnicas de "regra de três" ou uso de proporções diretamente proporcionais. Os estudantes usaram cálculos com as 4 operações básicas para determinar o produto mais barato, e nenhum grupo o fez de forma equivalente.

O segundo ponto é o fato de levantarem soluções depreendidas do fator mais barato, mas também do que é mais conveniente para as necessidades de cada um, chegando a entrar em quesitos ambientais e tomadas de decisões pertinentes a seu contexto, dando oportunidades de agir com equilíbrio e racionalidade diante das relações de consumo, com condições de identificar as melhores opções de negócios, as quais são elementos da Educação Financeira.

A abordagem contextualizada, que parte do universo do aluno real, e é conectada com os problemas autênticos da vida cotidiana é uma das características da RME. Por meio das intervenções do professor, cada aluno desempenhou papel de protagonista em seus processos de aprendizagem em um contexto baseado nas suas próprias produções e nas interações entre os colegas de sala. 
Fortalecer o desenvolvimento de estratégias e possibilidades de leitura do mundo frente às decisões financeiras, favorecendo satisfazer as necessidades da vida real dos indivíduos, em um contexto de sala de aula, é uma forma de desenvolver o letramento matemático, que é um dos maiores objetivos da educação.

\section{REFERÊNCIAS}

BRASIL. Parâmetros Curriculares Nacionais: Matemática. Brasília: MEC/SEF, 1998.

BRASIL. COREMEC. Educação Financeira nas escolas: Ensino Médio. Bloco 1 (Livro do professor). COREMEC, GAP, UNIBANCO, 2010.

\section{BRASIL. ENEF. Estratégia nacional de Educação Financeira - Plano Diretor da} ENEF: Anexos. 2011. Disponível em: < http://www.vidaedinheiro.gov.br/Legislacao /Arquivo/Plano-Diretor-ENEF-anexos-1.pdf> . Acesso em: 05 novembro 2016.

BURIASCO, R. L. C.; FERREIRA, P. E. A.; CIANI, A. B. Avaliação como prática de investigação (alguns apontamentos). Bolema: Boletim de Educação Matemática, Rio Claro-UNESP, v. 33, n. 22, p. 69-95, 2009.

DE LANGE, J. Mathematics for Literacy. In: MADISON, B. L.; STEEN, L. A. (Ed.). Quantitative Literacy: Why Numeracy Matters for Schools and Colleges. Princeton, New Jersey: National Council on Education and the Disciplines, 2003. p. 75-89.

FREUDENTHAL, H. Geometry between the devil and the deep sea. Educational Studies in Mathematics, Holanda, v. 3, n. 3-4, p. 413-435, 1971.

FREUDENTHAL, H. Matemática nova ou educação nova? Perspectivas, Portugal, v. 9, n. 3, p. 317-328, 1979.

FREUDENTHAL, H. Revisiting Mathematics Education. Netherlands: Kluwer Aca- 
demic Publishers, 1991.

FONSECA, M. C. F. R. A Educação matemática e a ampliação das demandas de leitura escrita da população brasileira. In: FONSECA, M. C. F. R. (Org.). Letramento no Brasil: habilidades matemáticas. São Paulo: Global, 2004. p. 11-28.

GRAVEMEIJER, K. O que torna a Matemática tão difícil e o que podemos fazer para o alterar? Educação matemática: caminhos e encruzilhadas. Lisboa: APM, 2005. p. 83-101.

HARMUCH, D. Tarefas para uma educação financeiro: um estudo. 2017. Dissertação (Mestrado) - Universidade Tecnológica Federal do Paraná, Londrina, PR.

HOFMANN, R.; MORO, M; L; F. Educação matemática, contexto e Educação financeira. In: CONFERÊNCIA INTERNACIONAL DE EDUCAÇÃO MATEMÁTICA, 18., Recife. Anais... 2011.

MENDES, M.T. Utilização da prova em fases como recurso para aprendizagem em aulas de cálculo. 2014. Tese (Doutorado em ensino de Ciências e Educação Matemática) - Universidade Estadual de Londrina, Londrina, PR.

MENDES, M.T.; HARMUCH, D. A matemática como um meio de organizar fenômenos da educação financeira: uma experiência didática. In: ENCONTRO NACIONAL DE EDUCAÇÃO MATEMÁTICA, 12., 2016, São Paulo. Educação matemática na contemporaneidade: desafios e possibilidades. Anais... São Paulo: Sociedade Brasileira de Educação Matemática, 2016. v. 1. p. 1-12.

LOPES, A. C. Os Parâmetros Curriculares Nacionais para o Ensino Médio e a submissão ao mundo produtivo: o caso do conceito de contextualização. Educação \& Sociedade, CEDES, Campinas, v. 23, n. 80, p. 389-403, set. 2002.

SANTOS, L. Dilemas e desafios da avaliação reguladora. In: MENEZES, L.; SANTOS, L.; GOMES, H.; RODRIGUES, C. (Ed.). Avaliação em Matemática: problemas e desafios Viseu: Secção de Educação Matemática da Sociedade Portuguesa de Ciências 
de Educação, 2008. p. 11-35.

VAN DEN HEUVEL-PANHUIZEN, M. Mathematics education in the Netherlands: a guided tour. In: FREUDENTHAL Institute. Utrecht: Utrecht University, 2000. CD-ROM.

VAN DEN HEUVEL-PANHUIZEN, M. Learning-teaching trajectories with Intermediate attainment targets. In: VAN DEN HEUVEL-PANHUIZEN, M. (Ed.). Children learn mathematics: a learning teaching trajectory with intermediate attainment targets for calculation with whole numbers in primary school. Groningen, The Netherlands: Wolters Noordhoff, 2001.

VAN DEN HEUVEL-PANHUIZEN, M. The Role of contexts in assessment problems in mathematics. For the Learning Mathematics, v. 25, n. 2, p. 2-9, 2005.

VAN DEN HEUVEL-PANHUIZEN, M. Reform under attack - Forty Years of Working on Better Mathematics Education thrown on the Scrapheap? No Way! In: THE ANNUAL CONFERENCE OF THE MATHEMATICS EDUCATION RESEARCH GROUP OF AUSTRALASIA, 2010. Conference... Austrália, 2010. p. 3-7.

Recebido em: 29 de agosto de 2017 Aceito em: 06 de novembro de 2017 